\title{
TRANSACTIONAL DISTANCE AND STUDENT SATISFACTION IN A POSTGRADUATE DISTANCE LEARNING PROGRAM
}

\author{
Vagelis GAVRILIS \\ ORCID: 0000-0002-2562-0041 \\ 4th High School of Argos \\ Argolida, GREECE \\ Dr. Ilias MAVROIDIS \\ ORCID: 0000-0002-2048-5733 \\ School of Humanities \\ Hellenic Open University \\ Athens, GREECE \\ Yiannis GIOSSOS \\ ORCID: 0000-0002-8145-2097 \\ School of Physical Education and Sport Science \\ University of Athens \\ Athens, GREECE
}

Received: 13/02/2019 Accepted: 12/03/2020

\begin{abstract}
The present study examines the three dimensions of the transactional distance theory of Moore and their correlation with student satisfaction, through a quantitative survey with data collected from 115 postgraduate students of the Hellenic Open University (H.O.U). The results indicate that students perceived low levels of teacher-student transactional distance and slightly higher, but still low, levels of student-student and student-content transactional distance. Moreover, they seem to be satisfied by their distant learning studies. Male students perceived lower levels of teacher-student and student-content transactional distance than female ones, while students with previous experience in distance learning perceived lower levels of student-student transactional distance than those without such experience. Statistically significant correlations exist between the three dimensions of transactional distance and satisfaction, with the strongest, negative correlation, observed between satisfaction and student-content transactional distance. Finally, statistically significant and, moderate to low, positive correlations were observed between the three types of transactional distance, indicating their interlinkages.
\end{abstract}

Keywords: Distance learning, transactional distance, interaction, teacher, student, satisfaction educational material content.

\section{INTRODUCTION}

The main characteristic of distance learning is that the learning process takes place without the physical presence of the teacher and the student in the same room (Cohen, Manion \& Morrison, 2007). Thus, there is a geographical distance between the teacher and the student. The first attempt to establish a comprehensive theory of distance learning began in 1972, leading to the theory of transactional distance (Moore, 1989, 1993). With this theory, Moore establishes the concept of distance in education in a social context and not in the usual physical interpretation (Saba, 2003). Moore emphasizes that in distance learning there is a gap, a distance between the teacher and the student (Moore, 1989). This distance, the transactional distance, is not only about the geographical distance that separates the teacher from the student. It refers to the non-interaction, or to a peculiar form of interaction, between teacher and student due to their geographical separation. Therefore, as transactional distance one could define the psychological and communicative space between a teacher and a student, or otherwise the distance between the teacher's input and the student's actual perception in an educational program (Moore, 1989). 
The theory of transactional distance in an educational program refers to a set of variables that can be grouped into three main categories: Dialogue, Structure, and Autonomy of the student (Moore, 1993). According to Giossos, Koutsouba, Lionarakis and Skavantzos (2009), transactional distance is the result of teaching as an initial action, while the dialogue, the autonomy and the structure of the curriculum describe the mechanisms by which it is produced. Additionally, transactional distance is perceived differently by each person depending on his/her experiences, cultural background and the educational level (i.e. undergraduate, postgraduate, etc.). Therefore, there is no general transactional distance, but a perceived transactional distance (Giossos, Mavroidis \& Koutsouba, 2016). Transactional distance is, in general, inversely proportional to the development of dialogue between teachers and students and proportional to the structure of the course and the students' autonomy (Moore, 1993). Moore (1993), in his theory, notes that transactional distance can also occur in face-to-face, traditional education and depends on the characteristics of those who learn and those who teach.

According to Moore (1989) there are three types of interaction, and therefore three types of transactional distance: (a) the transactional distance between students and teachers, which refers to the psychological, communicative and collaborative distance between them, (b) the transactional distance between the students, which refers to the psychological distance that the students "feel" among them, and (c) the transactional distance between students and content of the program, which indicates whether it satisfies the needs and expectations of the students. Hillman, Willis and Gunawardena (1994) added a fourth component to the model, the interaction between student and interface, due to the addition of high technology communications systems to mediate the communication process, corresponding to a fourth type of transactional distance, which refers to the extent to which the distribution system of the content/material is friendly and accessible to the user. The present work examines the first three types of transactional distance described by Moore, and their relation with student satisfaction in a postgraduate distance learning program.

\section{THEORETICAL FRAMEWORK}

\section{The Concept of Dialogue}

Dialogue is developed between teachers and students through an interaction or set of interactions which have a positive balance in the student's understanding process (Moore, 1993). Dialogue is influenced by the philosophy on the creators of a distance learning program, the design and philosophy of the program itself, the level of studies, the personality of the teachers and of the students, the subject matter/content of the program and environmental factors (Moore, 1993). Dialogue corresponds to the amount of control exercised by the student (Rovai, 2002). Increased dialogue results to an increased tendency to reduce transactional distance and to increase the sense that the student belongs to a community (Rovai, 2002). Dialogue is not a simple communication between the teacher and the student. It is a kind of cooperation between the two sides and is related to the understanding of the teacher, which aims at solving the problems of the student (Giossos, Koutsouba, Lionarakis \& Skavantzos, 2009). Moore (1993) highlights the qualitative characteristics of dialogue more than its quantitative characteristics.

\section{The Concept of Structure}

Structure expresses the rigidity or the flexibility of the educational objectives, the teaching methods and the ways of evaluating a program (Moore, 1993). It is a qualitative variable and depends on the means of communication, the philosophy and personality of the teachers, as well as on the particular characteristics of the students (Moore, 1993).

Dialogue is affected by the structure of a program. For example, a program with a high level of structure such as a TV show or an asynchronous video - does not offer opportunities to develop dialogue, since almost everything is predetermined, from the delivery of the course to the (lack of) interference and feedback by the learners. As a result, transactional distance increases with increased structure. On the contrary, through a videoconference where students can freely express themselves and the teacher's responses may vary depending on the dialogue developed, even for the same teaching unit/course, transactional distance is reduced (Moore, 1993). The parameters that decisively influence the structure of a distance learning program are: a) the way 
in which content is presented, b) the motivation of the students through targeted interventions, c) the motivation of the students towards analysis and criticism, d) the provision of personalized guidance, e) the practical application of the learning content and the evaluation of the acquired knowledge through tasks, and f) the extent to which students are enabled to create new knowledge by offering feedback to the program (Moore, 1993).

\section{The Concept of Autonomy}

Learner autonomy refers to the degree to which the student in a learning process - and in cooperation with the teacher - defines the objectives, the learning experiences and the decisions on the evaluation of a program. The educational system usually does not promote autonomy since it is often dominated by the students' dependence on the teacher (Moore, 1993). The student, due to distance from the teacher, should - to a significant extent - take the responsibility of his/her learning path. In distance learning programs, students with a high degree of autonomy seek for less dialogue and structure, while students with a low degree of autonomy seek for more (Moore, 1993).

\section{Satisfaction}

Satisfaction from an educational program is usually defined as the pleasure that the student gets from the results that he/she has achieved, from the forms of communication used, from the acceptance and understanding of the other, and especially from the level of the self-esteem he/she acquires (Vakoufari, Angelaki \& Mavroidis, 2014). The theory of transactional distance puts great emphasis on the continuous and effective contact of teachers and students, which also results in an increased satisfaction of the student. These two-way relationships involve dialogue, exchange of views, teamwork, and take place in an appropriate and specific learning environment. In an effective learning environment, the chances of students to overcome the obstacles increase, resulting in achieving the desired goals, which bring along the feeling of satisfaction (Vakoufari, Angelaki \& Mavroidis, 2014).

In the distance learning environment, the role and performance of the teacher plays an important role in the satisfaction of the student. The way the teacher guides the students in the learning process, together with the quality of the course, which is closely linked with its design and construction, are important factors for a satisfactory and effective learning experience. These features, which are particularly important for students, are significant elements of the quality of their educational experience and, therefore, an important predictor of their satisfaction (Joo, Lim \& Kim, 2013).

Krsmanovic, Djuric and Dmitrovic (2012) report the following main parameters related to the student's satisfaction:

- Functionality and update of the information on an online platform

- Completeness, clarity and quality of educational material

- Rate of provision of information to students

- Understanding the required tasks by the students

- Flexibility in forms of communication with the teachers and their availability

- Successful and effective communication between teachers and students

- Relationship between effort made and academic performance.

\section{LITERATURE REVIEW}

A number of recent studies examined the different dimensions and parameters of the transactional distance theory and on how they affect student satisfaction in distance learning or blended programmes. Ekwunife - Orakwue $\&$ Teng (2014) examined the impact of transactional distance dialogic interactions on student learning outcomes in online and blended environments. Their research concluded that student-content interaction has the greatest impact on learning outcomes compared to other forms of interaction, almost twice as much as student-teacher interaction and student - student interaction. While "dialogue" seems to 
contribute to the student satisfaction, it doesn't seem to be the same as to the academic performance. The level of "dialogue" is not affected by the age, while women are more likely to engage in communication than men.

Mbwesa's (2014) research correlates students' perceived satisfaction with transactional distance. This research has shown that student-student, teacher -student and student-content interaction are indicators of the perceived student satisfaction. The teacher-student interaction has the greatest impact on the transactional distance, making it necessary for students to be encouraged by the teacher as well as to support them in understanding the material.

Sher's (2009) research study evaluates the relationship of student-teacher interaction and student-student interaction, in relation to learning outcome and satisfaction in purely distance learning programs. This study concludes that both types of interaction play a critical role in learning outcome as well as in student satisfaction from the learning process. In addition, some students were more familiar with the program's online platform. However, this didn't affect the learning outcomes and the satisfaction of the students' sample as a whole.

The research of Stein, Wanstreet, Calvin, Overtoom, \& Wheaton (2005), illustrates students' cognitive satisfaction with the knowledge they acquire as a function of the structure of the distance learning program, the interaction and the existing know-how in relation to Information and Communication Technologies, within learning environments that are either supported or dependent solely on the internet. The results of their research show that cognitive satisfaction is directly related to satisfaction with the structure of the programs and with the satisfaction from the interaction, which is mainly initiated by the teachers. On the contrary, the format in which the teaching material is distributed does not appear to have an impact on satisfaction.

The research of Kassandrinou, Angelaki, \& Mavroidis (2014) examines the presence of transactional distance among students and its impact on the learning process in a mixed learning environment, that of the Hellenic Open University (HOU). The findings indicate that the transactional distance among students exists and is more geographical and partly emotional, as communication is limited. At the same time, transactional distance is influenced by factors such as the students' mentality, the teacher's encouragement to students to communicate with one another and the relatively limited opportunities offered by the HOU for interaction among students. In addition, the role of the teacher is crucial in facilitating communication among students.

The research of Ustati \& Hassan (2013) examines the interaction between teacher and learner through an online platform in a blended learning program in Malaysia, where there are face-to-face meetings once per month. The results of this study show that learners have access to up-to-date teaching materials through the platform, but at the same time they receive sufficient feedback from the teacher, although they would also like to have some form of modern communication. Also, it appears that the learners would like to develop more interaction with one another.

Miyazoe \& Anderson's (2010) research analyzes and compares the interaction of the student with the teacher, the fellow students and the content of four programs in a mixed learning environment. The results show that the teacher-learner interaction takes on higher priority in the in-person Counseling Group Sessions (CGS), while the student-content interaction takes priority in the online part of the program, affecting therefore more the satisfaction of students. At the same time, interaction with peers is increased in asynchronous online communication.

The study of Paul, Swart, Zhang and MacLeod (2015) examined transactional distance as a barrier to students' engagement with learning in the online environment, updating Zhang's scale of transactional distance. Their results indicated that all sub-constructs of the transactional distance theory, i.e. the transactional distance between student and teacher, student and student, and student and content, were significant predictors of student satisfaction in an online environment, with the student-teacher transactional distance being the stronger predictor.

Best and Conceicao (2017) explored the impact of transactional distance dialogic interactions on student satisfaction in an international blended learning master's degree program. The participants reported experiencing transactional distance for learner-learner and learner-teacher dialogic interaction elements and 
dissatisfaction in the online components of the program, but reported a sense of community and satisfaction for the face-to-face (in-person) elements of the program. Transactional distance for the dimension of learnercontent dialogic interaction was the highest observed and was attributed to the multi-institutional nature of the program. Students reported general satisfaction for the program overall.

According to Weidlich and Bastiaens (2018), regression models show that transactional distance is the most important predictor of satisfaction for an online learning population. They also note that according to their study, student-teacher and student-content transactional distance are significant predictors of student satisfaction, while - surprisingly according to the authors - student-student transactional distance shows no significant relationship with satisfaction. They also noted that the predictive capabilities of the sub-constructs amount to a much lower $\mathrm{R}^{2}$ in their study, compared to the study of Paul et al. (2015) in which $\mathrm{R}^{2}$ was 0.586 . They attributed this difference partly to the fact that in their study only student-teacher and student-content transactional distance were significant predictors of student satisfaction.

Overall, the literature review shows that all forms of interaction linked to the transactional distance theory are important for the satisfaction that students receive form a distant or blended learning program. At the same time, the relationship between each type of interaction and student satisfaction is complex and variant. For example, depending on the type of course and specificities of the population, student-content or teacherstudent interaction may be more important predictors of student satisfaction. Such type of information is very useful for the design of distance learning programs, of their learning material and of the training programs of tutors.

\section{METHODOLOGICAL FRAMEWORK OF THE SURVEY}

\section{Purpose and Research Questions}

As shown by the theoretical framework and the literature review, the theory of transactional distance is central for distance education and blended programs. The different types of interaction inherent to distance education programs are key for designing these programs effectively in order to optimize the learning outcomes and increase the satisfaction of students. This is especially important for the HOU, which is a relatively new university offering exclusively distance learning courses, and were relevant research studies are needed in order to better understand and improve the learning process.

Following the above, the purpose of this study is to investigate the three dimensions of transactional distance (student - teacher, student - student, student - content) and how they affect student satisfaction in the distance learning environment of a postgraduate course of the Hellenic Open University.

In this context, the research questions are:

- How do the students perceive each of the three dimensions of transactional distance, as well as the satisfaction from their studies?

- How are the above variables affected by student demographics (gender, age, professional status, academic level, previous experience in distance learning)?

- How each of the three dimensions of transactional distance is related to the other two dimensions and to student satisfaction?

\section{Educational Context}

Consisting of four separate Schools, namely Humanities, Science and Technology, Social Sciences and Applied Arts, the HOU is the unique Hellenic public educational institution offering exclusively distance learning courses to students throughout Greece as well as abroad since 1998. Undergraduate and postgraduate HOU courses are offered in Greek and are addressed to both Greek and non-Greek adult students, provided that the latter master the Greek language in an advanced level. Further information about the studies in HOU can be found in Kassadrinou, Angelaki, and Mavroidis (2014) and in Anagnostopoulou, Mavroidis, Giossos and Koutsouba (2015). 
HOU students following the Postgraduate Program on "Education Sciences" at the academic year 2016-7, when the current research was conducted, had to hand in four written assignments throughout the 10-month academic year, for each course module they enrolled in and sit exams at the end of it. Furthermore, each course module included five face-to-face Counseling Group Sessions (CGS). Participation in CGS is not compulsory. Students should plan their own study during each course module, while they are continuously supported by their tutor. To obtain their Master's Degree, students had to successfully complete four course modules and to submit a postgraduate dissertation.

It should be noted that the use of online tools in HOU has been increasing in recent years. Such tools include a web-based instructional environment (portal), where there is a dedicated website to each course module. The portal simplifies organizational procedures and provides forums for asynchronous tutor-student as well as student-student interaction.

The students upload their written assignments through the portal, and the tutor provides his/her feedback on the assignment to each individual student through the same system. Furthermore, the tutor provides information on the course and on the timelines through the portal to his group of students. Finally, students can pose questions to their tutor, either directly through email or through the portal. In the latter case, the post is seen by all the students in the group, who can also react and a discussion then opens. The most common subject of the posts and discussions is the written assignments and the questions relevant to them. The use of the forums by the students and tutors has been quite limited in the beginning, yet it is gradually increasing.

\section{Research Strategy}

A quantitative research approach was used, to extract cause-effect relationships under the prism of the interaction of variables (Bird, Hammersley, Gomm \& Woods, 1999). Correlation research was selected to examine the relation between the parameters.

\section{Participants}

A purposive sample of 115 postgraduate students was selected. The sample consisted of postgraduate students from six different course groups of the Postgraduate Program of Studies "Education Sciences" of the Hellenic Open University, during the academic year 2016 - 2017.

\section{Survey Tool}

In order to collect the data a questionnaire was used, consisting of three main sections. The first section included questions related to the demographic characteristics of the respondents, namely gender, age, occupational status, level of studies and previous experience in distance learning.

The second section included questions on the three dimensions of transactional distance experienced by the students. More specifically, there were eight questions related to the student - teacher transactional distance, eight questions related to the student - student transactional distance and eight questions related to the student-content transactional distance. All questions were closed and a five-point Likert scale was used (1. I fully disagree, 2. I partly disagree, 3. I am not sure, 4. I partly agree, 5. I fully agree).

Finally, the third section addressed the perceived satisfaction of students from their participation in the distance learning environment. It consisted of eight closed type questions and a five-point Likert scale was also used (1. none, 2. little, 3. moderate, 4. much, 5. very much).

The questionnaire was based on scales developed in previous studies, one for transactional distance and one for the satisfaction of students in distance learning programs. For transactional distance the scale of Mbwesa (2014) was used, with its questions adjusted to the framework of the Hellenic Open University. From Mbwesa's (2014) questionnaire two questions were removed for each axis of the transactional distance, since the content of these questions was not relevant to the organizational framework and the administrative and academic functioning of the Hellenic Open University. This does not affect the 
internal coherence of the questionnaire, since the Cronbach's Alpha in the Mbwesa (2014) survey/study showed that all sub-scale coefficients were above 0.7, while the Crombach Alpha was also measured in the present study. For measuring the satisfaction of students in distance learning programs, the scale of Arbaugh (2000) was used, as adapted for the framework of the Hellenic Open University by Vakoufari, Angelaki and Mavroidis (2014).

The data collection process took place during the third Counseling Group Session, in February 2017. The students were informed in detail about the purpose of the study. Participation in the study was voluntary and anonymous. Finally, participants were informed that they could have access to the results of the study if they so wished. For the analysis of data the statistical program SPSS 24 was used.

\section{Validity and Reliability}

The validity and reliability of the tool/scales has originally been tested in the previous surveys (Mbwesa, 2014; Vakoufari et al., 2014). The reliability test for the inner coherence of the subclasses was assessed by calculating the Cronbach's Alpha coefficient. All the coefficients of the questionnaire subsets, as calculated from these surveys, were above 0.7 . The lowest value was observed for the sub-scale measuring the transactional distance between the student and the educational content, which was $\mathbb{Q}=0.672$. This value is acceptable for behavioral studies (Mbwesa, 2014). In the present research the Cronbach's Alpha coefficients were also calculated and the results are shown in Table 1.

Table 1. Reliability factors for the questionnaire and its sub-scales

\begin{tabular}{lcc}
\hline Grouped variables & Number of questions & Coefficient a \\
\hline All scales & 32 & 0.895 \\
Transactional distance teacher- student & 8 & 0.849 \\
Transactional distance student - student & 8 & 0.911 \\
Transactional distance student - content & 8 & 0.693 \\
Satisfaction from distance learning studies & 8 & 0.902 \\
\hline
\end{tabular}

Overall, the reliability is quite high. The lowest value is observed for the scale measuring the transactional distance between the student and the content, which was $\square=0.693$, a value of approximately 0.7 , that remains acceptable for behavioral studies (Mbwesa, 2014).

\section{RESULTS}

\section{Demographic Information}

The results of the survey showed that 27 participants (23.5\%) were men, while $88(76.5 \%)$ were women. It also showed that 45 participants (39\%) were aged from thirty-one to forty years old, $41(35.7 \%)$ were aged from forty-one to fifty years old, $18(15.7 \%)$ were less than or equal to thirty years old and $11(9.6 \%)$ older than fifty years old. Regarding their professional status, the results showed that $99(86.1 \%)$ were fulltime employees, 10 (8.7\%) were unemployed and 6 (5.2\%) were employed part-time. Also, 80 (69.6\%) participants were university graduates, 31 (27\%) already held a postgraduate degree, $3(2.6 \%)$ were graduates of Technological Educational Institutes, while one participant $1(0.8 \%)$ held a $\mathrm{PhD}$. Finally, 84 participants $(73 \%)$ responded that they had no previous experience on distance learning. The demographic information is shown in Table 2. 
Table 2. Demographic Information

\begin{tabular}{lcc}
\hline Demographic Information & $\mathrm{v}$ & $\%$ \\
\hline SEX & 27 & 23.5 \\
Men & 88 & 76.5 \\
Women & & \\
AGE & 18 & 15.7 \\
$30<$ & 45 & 39.0 \\
$30-40$ & 41 & 35.7 \\
$41-50$ & 11 & 9.6 \\
$50>$ & & \\
EMPLOYMENT STATUS & 10 & 8.7 \\
Unemployed & 99 & 86.1 \\
Part-time employees & 6 & 5.2 \\
Full-time employees & & \\
EDUCATIONAL LEVEL & 80 & 69.6 \\
University graduates & 31 & 27.0 \\
Postgraduate degree & 3 & 2.6 \\
Technological Educational Institutes & 1 & 0.8 \\
PhD & & \\
EXPERIENCE ON DISTANCE LEARNING & 31 & 27.0 \\
Previous experience on distance learning & 84 & 73.0 \\
No previous experience on distance learning & & \\
\hline
\end{tabular}

\section{Descriptive Analysis Results}

Descriptive statistics, such as mean score and standard deviation, were used since the variables under examination were ordinal. Table 2 presents the mean value and standard deviation of the transactional distance between the teacher and the student, the student - student transactional distance, the transactional distance between the student and the content, and the satisfaction from the distance learning program. It should be noted that the questionnaire was structured so that higher values of parameters correspond to higher levels of interaction and, therefore, lower levels of transactional distance.

Table 3. Mean values and standard deviation of the variables

\begin{tabular}{ccc}
\hline Variable & Average & Standard deviation \\
\hline Teacher- student transactional distance & 3.82 & 0.97 \\
Student - student transactional distance & 3.32 & 1.15 \\
Student - content transactional distance & 3.31 & 1.08 \\
Satisfaction with distance learning & 3.62 & 1.11 \\
\hline
\end{tabular}

\section{Demographic Differences}

In order to select whether to use parametric or non-parametric tests, the values of the warp and the bending of the dependent variables were examined. All variables were found to have a normal distribution, and therefore for the analysis of inductive statistics, parametric criteria were used, such as $\mathrm{t}$ - test and ANOVA (Cohen, 1988). The analysis of gender, age, occupational status, academic level and experience in distance learning that follows focuses only on those results where statistically significant differences were observed. 
In order to investigate the possible differences in relation to gender, a $\mathrm{t}$ - test was performed. The analysis showed a statistically significant difference in the teacher - student transactional distance in relation to gender (Cohen's $d$ index equal to 0.39), with lower levels of teacher - student transactional distance observed for men. Also, the analysis showed a statistically significant difference of the transactional distance between the student and the content, in relation to the gender (Cohen's $\mathrm{d}$ index equal to 0.52), with lower levels of student - content transactional distance observed for men.

Table 4. Results of $\mathrm{t}$ - test in relation to gender differences

\begin{tabular}{lccccccc}
\hline & \multicolumn{2}{c}{ Men } & \multicolumn{2}{c}{ Women } \\
\hline & M & SD & M & SD & t & p & Cohen's d \\
\hline Teacher - student & 3.99 & 0.46 & 3.75 & 0.73 & 2.02 & 0.04 & 0.39 \\
Student - student & 3.16 & 0.73 & 3.37 & 0.96 & -1.21 & 0.23 & \\
Student - content & 3.53 & 0.47 & 3.25 & 0.64 & 2.17 & 0.03 & 0.52 \\
Satisfaction & 3.84 & 0.76 & 3.55 & 0.88 & 1.52 & 0.13 & \\
\hline
\end{tabular}

Note: $p<0.05$

In order to investigate the possible differences in relation to previous experience in distance learning, a $t$ - test for independent samples was performed. The analysis showed that the transactional distance among students has a statistically significant difference in relation to the experience in distance learning (Cohen's $\mathrm{d}$ index equal to 0.28 ), with lower levels of student - student transactional distance observed for students with previous experience in distance learning.

Table 5. Results of $\mathrm{t}$ - test in relation to differences in experience in distance learning

\begin{tabular}{|c|c|c|c|c|c|c|c|}
\hline & \multicolumn{2}{|c|}{ With experience } & \multicolumn{2}{|c|}{ Without experience } & \multirow[b]{2}{*}{$\mathrm{t}$} & \multirow[b]{2}{*}{$p$} & \multirow[b]{2}{*}{ Cohen's d } \\
\hline & $M$ & SD & $M$ & SD & & & \\
\hline Teacher - student & 3.84 & 0.66 & 3.75 & 0.74 & 0.619 & 0.537 & \\
\hline Student - student & 3.48 & 0.85 & 2.88 & 0.93 & 3.23 & 0.002 & 0.28 \\
\hline Student - content & 3.28 & 0.64 & 3.4 & 0.54 & -1.009 & 0.315 & \\
\hline Satisfaction & 3.84 & 0.82 & 3.55 & 0.95 & 0.505 & 0.614 & \\
\hline
\end{tabular}

Note: $p<0.05$

\section{Correlation Analysis}

The Spearman's rho criterion was used to examine the correlation between the examined variables, since the variables were of an ordinal scale (Cohen, 1988). The results presented in Table 5, suggest the existence of statistically significant correlations among variables. It should be noted that the questions were set in such a way that higher parameter values correspond to increased levels of interaction and therefore decreased levels of transactional distance. In particular, a small but statistically significant positive correlation exists between (a) the student-student interaction and satisfaction (and therefore a negative correlation between the student - student transactional distance and satisfaction), $\mathrm{r}=0.101, \mathrm{p}<0.01$, and (b) the student-student transactional distance and the student-content transactional distance, $r=0.168, \mathrm{p}<0.05$. Also, statistically significant, moderate, positive correlations exist between (a) the teacher-student interaction and satisfaction (and therefore a negative correlation between the teacher - student transactional distance and satisfaction), $r=0.335, p<0.01$, (b) the teacher-student transactional distance and the student-student transactional distance, $\mathrm{r}=0.3, \mathrm{p}<0.01$, and (c) the teacher-student transactional distance and the student-content transactional distance, $r=0.323, p<0.01$.

Finally, statistically significant, strong, positive, correlation occurs between the interaction between the student and the content of the distance learning program and satisfaction (and therefore a negative correlation between the student - content transactional distance and satisfaction), $r=0.618, p<0.01$. 
Table 6. Correlation between the examined parameters

\begin{tabular}{|c|c|c|c|c|c|}
\hline Spearman's rho & & Teacher-student & Student-student & Student-Content & Satisfaction \\
\hline \multirow[t]{3}{*}{ Teacher-student } & Correlation Coefficient & 1.0 & $0.3^{* * *}$ & $0.323^{* *}$ & $0.335^{* *}$ \\
\hline & Sig. (1-tailed) & - & 0.001 & 0.00 & 0.00 \\
\hline & $\mathrm{N}$ & 115 & 115 & 115 & 115 \\
\hline \multirow[t]{3}{*}{ Student-student } & Correlation Coefficient & $0.3^{* *}$ & 1.0 & $0.168^{*}$ & 0.101 \\
\hline & Sig. (1-tailed) & 0.01 & - & 0.036 & 0.141 \\
\hline & $\mathrm{N}$ & 115 & 115 & 115 & 115 \\
\hline \multirow[t]{3}{*}{ Student-content } & Correlation Coefficient & $0.323^{* *}$ & $0.168^{*}$ & 1.0 & $0.618^{* *}$ \\
\hline & Sig. (1-tailed) & 0.00 & 0.036 & - & 0.00 \\
\hline & $\mathrm{N}$ & 115 & 115 & 115 & 115 \\
\hline \multirow[t]{3}{*}{ Satisfaction } & Correlation Coefficient & $0.335^{* *}$ & 0.101 & $0.618^{* *}$ & 1.0 \\
\hline & Sig. (1-tailed) & 0.00 & 0.141 & 0.00 & - \\
\hline & $\mathrm{N}$ & 115 & 115 & 115 & 115 \\
\hline
\end{tabular}

** Correlation is significant at the 0.01 level (1-tailed).

${ }^{*}$ Correlation is significant at the 0.05 level (1-tailed).

\section{DISCUSSION}

The findings of the descriptive statistical analysis suggest that students have a positive perception of their communication and collaboration with the teacher and of the support provided by the latter. This indicates that they perceive that the transactional distance between teachers and students remains low. The studies of Ekwunife - Orakwue and Teng (2014), Falloon (2011) and Mbwesa (2014), also indicated low levels of teacher-student transactional distance in distance learning programs. It shows that well-designed programs result to an increased satisfaction of students from their interaction with the teacher and the development of dialogue in an online / distance learning environment. The differences observed between these studies and that of Ustati and Hassan (2013) may be attributed to the different research approaches and the very small sample used by Ustati and Hassan (2013) - who used a qualitative approach, with a very limited number of two informants - and possibly, to the different curricula and design of the courses/ institutions.

In relation to student-student interaction, the results also indicate low levels of transactional distance, which is attributable to the communication, the cooperation and the mutual support among students. However, student-student interaction is not as effective as student-teacher interaction. The above findings are consistent with the results of other studies, which show a relatively high level of interaction, and therefore a relatively low level of transactional distance among students (Ekwunife - Orakwue \& Teng, 2014; Falloon, 2011; Mbwesa, 2014; Miyazoe \& Anderson, 2010; Sher, 2009; Stein, Wanstreet, Calvin, Overtoom \& Wheaton, 2005). At the same time, there is also a general agreement with the qualitative studies of Kassandrinou, Angelaki and Mavroidis (2014) and Ustati and Hassan (2013), which suggest that the level of studentstudent interaction is lower than that of student-tutor interaction. Indeed, as suggested in the study of Kassandrinou et al. (2014), which was performed in the same educational environment as the present study, the limited face-to-face interaction and the lack of group assignments lead to an increased student-student transactional distance (in relation to teacher-student transactional distance). This is enhanced by the fact that the postgraduate students were accustomed to traditional face-to-face courses during their undergraduate studies, where they interacted more easily with their fellow students. 
In relation to the transactional distance between the students and the content of the distance education program, the results show that students believe that the content of the distance education program meets their needs, with the student-content transactional distance being at a similar level as the student-student transactional distance. These results are in agreement with the results of similar studies, such as those of Miyazoe and Anderson (2010), Mbwesa (2014) and Stein et al. (2005), which suggest similar levels of student interaction with the educational content. The results of Ustati and Hassan (2013) suggest lower levels of student-content interaction, this being attributed to technical issues of the online platform used, and possibly to the low number of informants.

In relation to student satisfaction, the results show that students are quite satisfied from their distance learning studies, which is a positive finding, especially noting that their previous educational experiences are mainly from conventional education. The high levels of perceived satisfaction are in agreement with findings from studies conducted in other educational environments, such as those of Sher (2009) and Stein et al. (2005), and also consistent with the findings from other studies in HOU, such as the study of Anagnostopoulou, Mavroidis, Giossos and Koutsouba (2015).

Regarding the effects of the demographic characteristics of the sample, a statistically significant, quite high, difference was observed regarding the levels of transactional distance between the students and the content of the distance program in relation to gender. Furthermore, a statistically significant, moderate, difference was observed regarding the level of transactional distance between the students and the teacher in relation to gender. The above is in line with the results of Ekwunife - Orakwue and Teng (2014), who observed that the gender dimension plays an important role in distance learning. It appears that women perceive a larger transactional distance between themselves and the content of the educational material and a relatively larger transactional distance between themselves and the teacher. The higher transactional distance perceived by female students, especially in relation to the educational content, may be attributed to their increased need for personal contact and preference for face-to-face meetings as well as to their increased stress in relation to information and communication technologies (Moss, 2004; Muller, 2008; Zembylas, 2008), since students in distance education work most of the time alone with the educational material. Finally, a statistically significant difference in relation to gender is not observed for the parameter of student satisfaction, which is in agreement with the findings of Anagnostopoulou et al. (2015) and Sher (2009).

The results also suggest that there was a statistically significant difference in the level of student-student transactional distance in relation to their previous experience in distance learning. Students who have previous experience in distance learning perceive a lower level of transactional distance between students, since they are more accustomed to the distance education context and realize the importance of their interaction with peers, which they are not afraid to pursue to a higher degree. Sher (2009) notes that students who have prior experience with the distance / online learning context could feel more comfortable as compared to those who have no such experience.

The examination of the correlation between the examined parameters revealed that the correlation between the student-teacher transactional distance and the student satisfaction from the educational program was statistically significant and moderate, with the satisfaction increasing as transactional distance decreases. This correlation indicates the importance that students place in the interaction with their tutor in a distance learning environment, and therefore the importance of the tutor's role for student satisfaction. Similar findings were observed in the studies of Ekwunife - Orakwue and Teng (2014), Mbwesa (2014), Stein et al. (2005), as well as of Sher (2009) who indirectly addressed satisfaction through the learning outcomes.

Furthermore, the results of this study also showed a statistically significant, but very low, correlation between the student-student transactional distance and satisfaction, with the satisfaction increasing as transactional distance decreases. Ekwunife - Orakwue \& Teng (2014), Mbwesa (2014), Sher (2009) and Stein et al. (2005), also found a positive relation between the student-student interaction and satisfaction. In their case, this relation was stronger than in the present study, possibly due to the different types of programmes examined and to the larger previous experience of their respondents with distance education programs. Finally, the correlation between the student-content transactional distance and satisfaction was statistically significant and strong, with the satisfaction increasing as transactional distance decreases. This indicates that the interaction of the student with the educational material is an important predictor of his/her satisfaction from the studies, as also indicated by Ekwunife - Orakwue and Teng (2014), Mbwesa (2014) and Stein et al. (2005), reconfirming the central role of the educational material in distance education. 
In relation to the correlation between the three dimensions of transactional distance, the results showed that (a) the correlation between the student-teacher transactional distance and the student-student transactional distance was statistically significant and moderately positive, (b) the correlation between the studentteacher transactional distance and the student-content transactional distance was statistically significant and moderately positive, and (c) the correlation between the student-student transactional distance and the student-content transactional distance was statistically significant and positive, but low. These findings, which are consistent with those of Mbwesa (2014) and Stein et al. (2005), show that the three main dimensions of transactional distance are related and that the interaction of the students with their teacher, their peers and the educational content are interlinked. The three types of interaction need to be pursued in an integrated manner to lead to a successful distance education program.

\section{CONCLUSIONS}

The purpose of this study was to investigate the levels of transactional distance perceived by postgraduate students of the Hellenic Open University and their correlation with the degree of students' satisfaction from their distance learning studies. The first research question was how students perceive each of the three dimensions of transactional distance according to Moore (student - teacher, student - student, student content), as well as the satisfaction from their studies. The analysis of the research results revealed that learners appreciate to a greater extent the communication, collaboration and support with/from their teachers, and to a lesser extent the interaction with their peers and with the content of the distance program, while they seem in general satisfied with their distance learning studies.

The second research question referred to whether these variables are affected by student demographics (gender, age, occupational status, academic level, previous experience in distance learning). The results showed that men have a more positive opinion than women regarding whether the content of the distance program covers their distance learning needs, and therefore they experience a lower level of student -content transactional distance than women. It also appears that men have a more positive attitude in relation to the communication, support and collaboration with the teacher and therefore they perceive lower levels of student - teacher transactional distance than women. Finally, students who have previous experience in distance learning have a more positive opinion about the communication, support and cooperation with their peers and therefore experience lower levels of student-student transactional distance, compared to students with less experience in distance learning.

Finally, the correlation between the examined variables showed that statistically significant correlations exist between satisfaction and the three dimensions of transactional distance, with the strongest, negative correlation, observed with the student-content transactional distance and the weakest, negative, correlation with the student-student transactional distance (with the correlation between satisfaction and teacher-student transactional distance positioned in between). This confirms the importance that the educational material has for distance learning, with the role of the tutor also being of significance. Furthermore, it indicates the need for the tutors and the educational organization/institution to explore ways to promote student-student interaction so that it has a more prominent role in the distance education program. Regarding the correlation between the different dimensions of transactional distance, the results showed statistically significant and, moderate to low positive correlations between all types of transactional distance, indicating the interlinkages existing between the three dimensions of transactional distance according to Moore.

It should be noted that the study has certain limitations: it was conducted in the framework of HOU, and the generalization of the findings regarding other distance learning environments needs caution. Furthermore, the study focused on a limited number of postgraduate students selected via purposive sampling. In this respect a larger sample, chosen with random sampling, representing the total HOU student body would enable further examination of the relation between the dimensions of transactional distance and student satisfaction. 


\title{
BIODATA and CONTACT ADDRESSES of AUTHORS
}

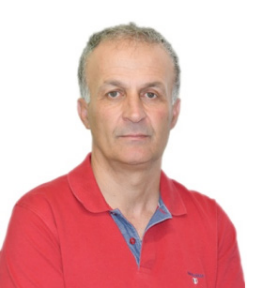

Vagelis GAVRILIS is a Teacher of Physical Education with many years of professional experience. He currently works in 4th High School of Argos in Argolida, Greece. He obtained his Master's Degree Med "Master's in Education", Hellenic Open University in September 2017. His academic interest areas are mainly focused on the distance education, the integration of technology in education and digital learning objects. The use of educational technologies in physical education and social media are also included in his interests.

\section{Vagelis GAVRILIS}

4th High School of Argos

Address: Zografou 9, 21232, Argos, Greece

Phone: +30 6976555642

E-mail: vagelisgavrilis@gmail.com

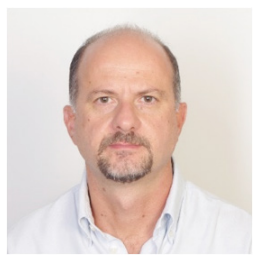

Dr. Ilias MAVROIDIS, $\mathrm{PhD}$. has a first degree in Chemical Engineering from the National Technical University of Athens, Greece. He holds an MSc and a PhD from the Department of Chemical Engineering of the University of Manchester/UMIST, United Kingdom, and a MEd in Adult Education from the Hellenic Open University. Dr. Mavroidis is a tutor at the Hellenic Open University since 2000, mainly at the modular course on "Open and Distance Education". He has published more than 110 refereed papers in scientific journals and conference proceedings, both in the field of environmental management/air pollution and in the field of distance learning. His research interests in the field of distance learning include the use of educational technologies, the empirical study of the transactional distance theory, the community of inquiry model, and the factors affecting student satisfaction.

\section{Ilias MAVROIDIS}

School of Humanities, Hellenic Open University, Greece Address: 51, Eftichias Street, GR-14121, Athens, Greece Phone: +30 6937163266

E-mail: imavr@tee.gr

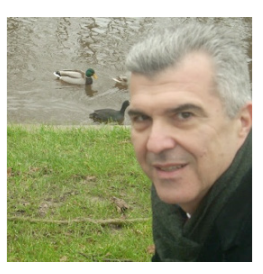

Yiannis GIOSSOS is an Associate Professor of Sports Philosophy at the National and Kapodistrian University of Athens. He teaches Sports Ethics and Philosophy of Education. $\mathrm{He}$ is also a tutor at the Hellenic Open University since 2000, mainly at the modular course on "Open and Distance Education". His research interests focus on the History and Philosophy of Physical Education, on the Philosophy of Education and Distance Learning.

\author{
Yiannis GIOSSOS \\ School of Physical Education and Sport Science University of Athens \\ Address: Ethnikis Antistasis 41, Dafni 17237, Athens Greece \\ Phone: +30 6955825959 \\ E-mail: ygiossos@phed.uoa.gr
}




\section{REFERENCES}

Anagnostopoulou, E., Mavroidis, I., Giossos, Y., \& Koutsouba., M. (2015). Student satisfaction in the context of a postgraduate programme of the Hellenic Open University. Turkish Online Journal of Distance Education, 16(2), 226-238. Doi:10.17718/tojde.52944.

Arbaugh, J.B. (2000). Virtual classroom characteristics and student satisfaction with internet based MBA courses. Journal of Management Education, 24(1), 32-54. DOI: 10.1177/105256290002400104.

Best B,. \& Conceicao, S.C.O. (2017). Transactional Distance Dialogic Interactions and Student Satisfaction in a Multi-Institutional Blended Learning Environment. European Journal of Open, Distance and E-Learning, 20(1), 138-152. DOI: 10.1515/eurodl-2017-0009.

Bird, M., Hammersley, M., Gomm, R., \& Woods, P. (1999). Educational research in practice. Study Manual. Patras, HOU Press.

Cohen, J (1988). Statistical power analysis for the behavioral sciences ( $2^{\text {nd }}$ ed.). Hillsdale, NJ: Erlbaum.

Cohen, L., Manion, L., \& Morrison, K. (2007). Research methods in education (6th ed). London and New York: Routledge.

Ekwunife-Orakwue, K. C., \& Teng, T. L. (2014). The impact of transactional distance dialogic interactions on student learning outcomes in online and blended environments. Computers and Education, 78, 414-427.

Falloon, G. (2011). Making the connection: Moore's theory of transactional distance and its relevance to the use of a virtual classroom in postgraduate online teacher education. Journal of Research on Technology in Education, 43(3), 187-209. Doi:10.1080/15391523.2011.10782569.

Giossos, Y., Koutsouba, M., Lionarakis, A., \& Skavantzos, K. (2009). Reconsidering Moore’s transactional distance theory. European Journal of Open, Distance and e-Learning, 12(2). Retrieved from: http:// www.eurodl.org/?article $=373$.

Giossos, Y., Mavroidis, I., \& Koutsouba, M. (2016). Development of an instrument for measuring LearnerTeacher transactional distance. American Journal of Distance Education, 30(2), 98-108.

Hillman, D. C., Willis, D. J., \& Gunawardena, C. N. (1994). Learner-interface interaction in distance education: An extension of contemporary models and strategies for practitioners. The American Journal of Distance Education, 8(2), 30-42.

Joo, Y. J., Lim, K. Y., \& Kim, J. (2013). Locus of control, self-efficacy, and task value as predictors of learning outcome in an online university context. Computers \& Education, 62, 149-158.

Kassandrinou, A., Angelaki, C., \& Mavroidis, I. (2014). Transactional distance among open university students: How does it affect the learning process? European Journal of Open, Distance and e-Learning, 17(1). 26-42

Krsmanovic, M., Djuric, M., \& Dmitrovic, V. (2012). A survey of student Satisfaction with distance learning at faculty of organizational sciences, University of Belgrade. . In Virtual and Networked Organizations, Emergent Technologies and Tools: First International Conference, ViNOrg 2011, Ofir, Portugal, July 6-8, 2011. Revised Selected Papers (Vol. 248, p. 111). Springer.

Mbwesa, J. K. (2014). Transactional distance as a predictor of perceived learner satisfaction in distance learning courses: A case study of Bachelor of Education Arts Program, University of Nairobi, Kenya. Journal of Education and Training Studies, 2(2), 176-188. Doi:10.11114/jets.v2i2.291

Miyazoe, T., \& Anderson, T. (2010). Empirical research on learners' perceptions: Interaction equivalency theorem in blended learning. European Journal of Open, Distance and e-Learning, 13(1). Retrieved from http://www.eurodl.org/?article=397

Moore, M. G., (1989). Three types of interaction. The American Journal of Distance Education, 3(2), 1-7.

Moore, M.G. (1993). Theory of transactional distance. In D. Keegan (ed.), Theoretical principles of distance education (pp. 22-38). New York: Routledge. 
Moss, D. (2004). Creating space for learning: Conceptualising women $\&$ higher education through space \& time. Gender \& Education, 16(3), 283-302.

Muller, T. (2008). Persistence of women in online degree completion programs. International Review of Research in Open \& Distance Learning, 9(2), 1-18.

Paul, R. C., Swart, W., Zhang, A. M., \& MacLeod, K. R. (2015). Revisiting Zhang's scale of transactional distance: Refinement and validation using structural equation modeling. Distance Education, 36(3), 364-382.

Rovai, A. P. (2002). Building sense of community at a distance. International Review of Research in Open and Distributed Learning, 3(1), 1-16.

Saba F. (2003). Distance education theory, methodology, and epistemology: A pragmatic paradigm. In Michael G. Moore \& William G. Anderson (Eds.), Handbook of distance education (pp. 3-20). Mahwah, NJ. Lawrence Erlbaum Associates.

Sher A. (2009). Assessing the relationship of student-instructor and student-student interaction to student learning and satisfaction in Web-based online learning environment. Journal of Interactive Online Learning, 8(2), 102-120.

Stein, D. S., Wanstreet, C. E., Calvin, J., Overtoom, C., \& Wheaton, J. E. (2005). Bridging the transactional distance gap in online learning environments. American Journal of Distance Education, 19(2), 105118. Doi:10.1207/s15389286ajde1902_4

Ustati R., \& Hassan. S. (2013). Distance learning students' need: Evaluating interactions from Moore's theory of transactional distance. Turkish Online Journal of Distance Education, 14(2), 292-304.

Vakoufari, M., Angelaki, C., \& Mavroidis, I. (2014). Self-esteem and loneliness as factors affecting distance learning students. European Journal of Open, Distance and e-Learning, 17(2), 100-116.

Weidlich, J., \& Bastiaens, T. J. (2018). Technology Matters - The Impact of Transactional Distance on Satisfaction in Online Distance Learning. The International Review of Research in Open and Distributed Learning, 19(3). https://doi.org/10.19173/irrodl.v19i3.3417

Zembylas, M. (2008). Adult learners' emotions in online learning. Distance Education, 29(1), 71-87. 